\title{
SEISMIC ANALYSIS OF A HIGHWAY BRIDGE CONSIDERING SOIL-STRUCTURE INTERACTION EFFECTS
}

BY

\author{
Toshio IWASAKI* and Kazuhiko KAWASHIMA**
}

\begin{abstract}
SYNOPSIS
In analyzing seismic behaviour of highway bridges constructed on soft soil deposits, it is important to take account of soil-structure interaction effects. In this paper, seismic response of a bridge pier-foundation is investigated based on earthwuake acceleration records measured simultaneously on the pier crest and on the ground surface near that bridge. Four motions were used in the analysis, i.e., two were induced by two earthquakes with magnitudes of 7.5 and 6.6 , respectively; and two by their aftershocks. In the former two earthquakes, the maximum accelerations were 186 and 438 gals on the ground surface, and 310 and 230 gals on the pier top, respectively. Analyses of frequency characteristics of the motions showed that the predominant frequencies of pier-foundation were always approximately identical with the fundamental natural frequency of the subsoil. Analyses of micro-tremors measured at the sites revealed that the natural frequency of the pier-foundation system is higher than the fundamental natural frequency of the subsoil. Analytical models were formulated to calculate the seismic response of the pier-foundation assuming the subsoil and pier-foundation to be a shear column model with an equivalent linear shear modulus and an elastically supported beam on the subsoil, respectively. Bedrock motions were computed from the measured ground surface motions and then applied to the bedrock of the analytical model. The seismic responses of pier-foundation were thus caluclated and compared with the measured records giving a good agreement.
\end{abstract}

\section{INTRODUCIION}

In the past, numerous highway bridges have suffered extensive damage due to strong motion earthquakes. Seismic damage to bridges consisting of simply supported girders or trusses rested on massive piers and abutments were commonly caused by foundation failures resulting from excessive ground deformations and/or loss of stability and bearing capacity of the foundation soils. As a direct result, the substructures often tilted, settled, or sometimes overturned, and these large displacements of the supports caused relative shifting of the superstructures, induced failures of the bearing supports, and even caused dislodging of the spans from their supports.

In has been well recognized from these evidences that the influences of surrounding subsurface ground are very important for the seismic responses of foundations deeply embedded in the ground, and considerable interest was concentrated on the soil-structure interaction effects of such structures through model experiments and theoretical analyses. However very limited researches have been undertaken in studying seismic responses of actual foundations during high intensity seismic excitations since only few data have been available for such purposes. This investigation presents the results of observation of seismic motions on a bridge pier and on the ground surface nearby with high accelerations which were measured during four earthquakes, and also correlates the pier motions measured with the pier motions analyzed using the ground surface acceleration records.

* Head, Ground Vibration Section, Earthquake Disaster Prevention Division, Public Works Research Institute, Ministry of Construction, Chiba, Japan.

** Research Engineer, Ground Vibration Section, Earthquake Disaster Prevention Division, Public Works Research Institute, Ministry of Construction

\section{STRUCTURAL AND SITE CONDITIONS OF THE BRIDGE}

The Itajima Bridge studied is a fivespanned simply-supported plate girder bridge as shown in fig. 1. The strong-motion-acceleration observations have been conducted since 1966 at a crest of one of the piers and on the free-field ground surface located about $200 \mathrm{~m}$ apart from the pier. Two SMAC-B2 type accelerographs are set at the both sites to measure accelerations in the longitudinal, transverse and vertical directions of the bridge axis.

Ground surveys were performed at the both sites and information on soil profile, $\mathrm{N}$-value of standard penetration test, and shear wave velocities were obtained. Fig. 2 shows the soil profiles and $\mathrm{N}$-values at the sites. It is recognized from the results that the ground conditions are essentially the same between the two sites, i.e., the soil profiles consist of upper soft loam stiff gravel formations with the averaged $\mathrm{N}$-value of approximately 7 and lower stiff gravel formations with the averaged N-values of 30 or more. It is also recognized that the ground condition seems to be continuous between the two sites. The shear wave velocities of the upper and lower formations were estimated to be approximately 130 and $480 \mathrm{~m} / \mathrm{sec}$., respectively. The gravel formations were assumed to be the base-rock at the sites in calculating seismic responses of the ground and foundation in the following paragraph.

\section{STRONG-MOTION-ACCELERATION RECORDS}

Four simultaneous strong-motion-acceleration records have been obtained at the Itajima Bridge as summarized in Table 1 which were induced by four earthquakes, i.e., main and after shocks of both the Hyuganada Earthquake of April 1, 1968 and the Bungosuido Earthquake of August 6, 1968, which are designated herein as A, B, C and D Earthquakes, respectively. Figs. 3, 4 and 5 show the acceleration records thus obtained in the longitudinal 


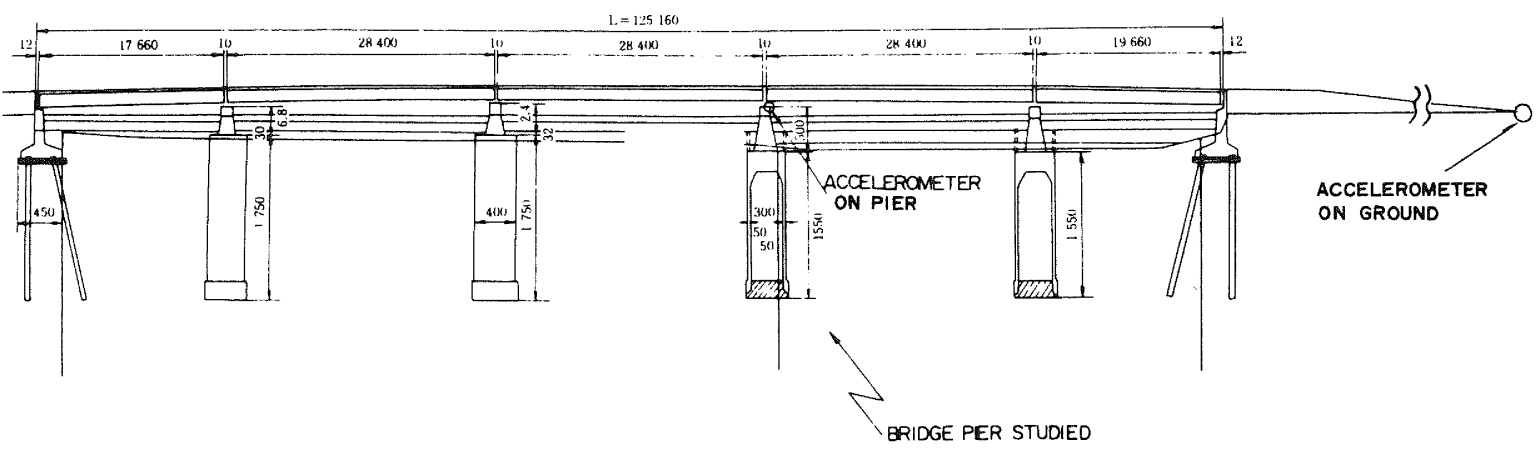

Fig. 1 GENERAL VIEW OF THE ITAJIMA BRIDGE

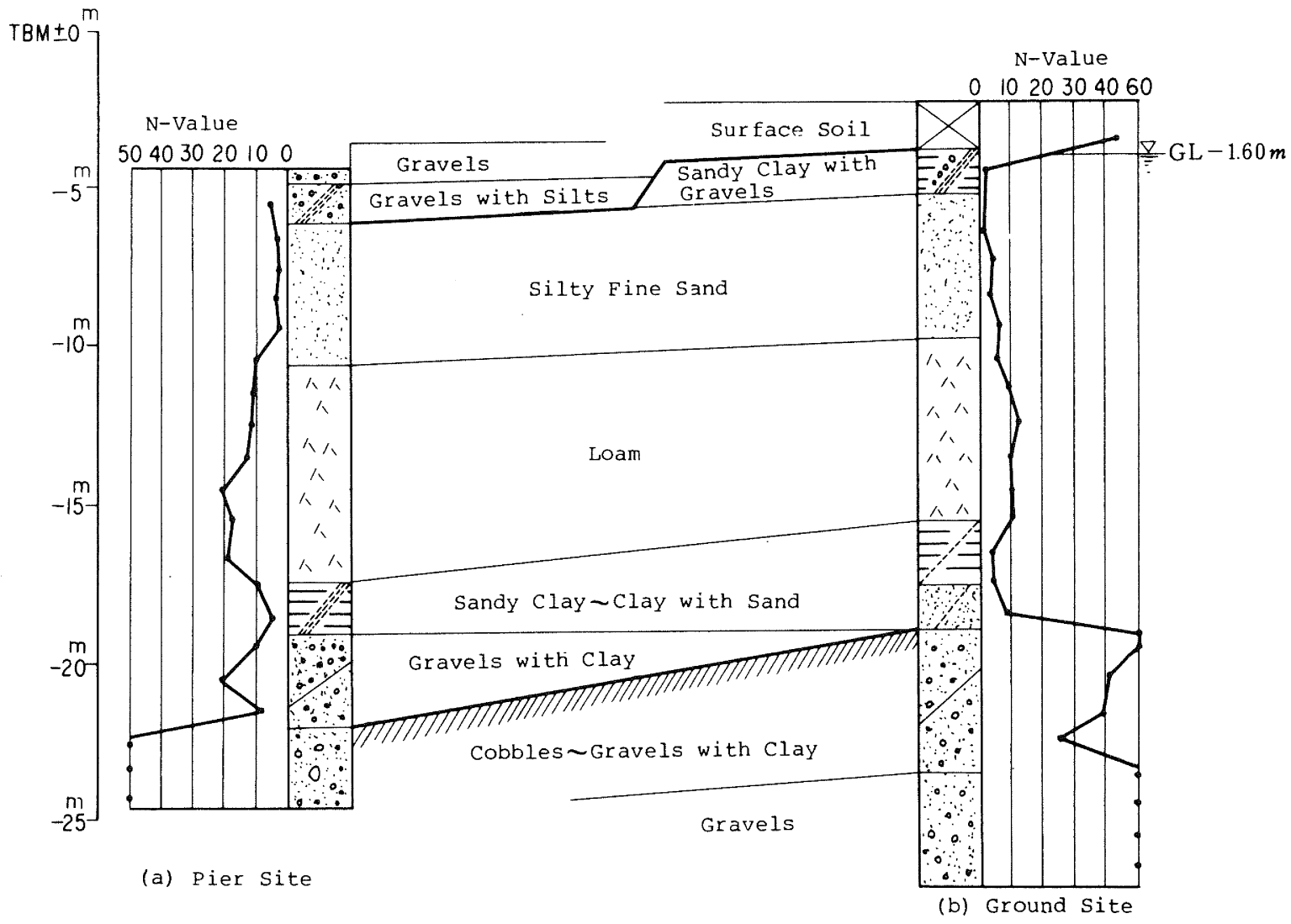

Fig. 2 SOIL PROFILE AT THE PIER SITE AND THE GROUND SITE 
and transverse directions of the bridge axis. In the D-Earthquake, accelerations on the pier could not be unfortunately recorded and only the maximum value of acceleration was obtained. It should be noted here that although the seismic response accelerations achieved at the pier crest were very high, superstructures and foundations of the Itajima Bridge suffered no structural damages through any of these four earthquakes.

Fig. 6 represents amplifications of maximum accelerations between the ground surface and the crest of pier. It can be recognized from this result that the amplifications of maximm accelerations are very much different between the Hyuganada Earthquake (A and B - Earthquakes) and the Bungosuido Earthquake (C and D - Earthquakes), i.e., the amplification factors are in the range of 1.1- 1.7 in the case of A and B - Earthquakes, whereas they are in the range of $0.4-0.6$ in the $C$ and D - Earthquakes. The frequency characteristics of the motions were then investigated. Predominant frequencies of the records are summalized in Table 2 , based on the power spectra presented in fig. 7. It is understood from the result that in the AEarthquake the predominant frequency of the ground is approximately equal to that of the pier motion, namely, approximately $1.5 \mathrm{~Hz}$ in the longitudinal motion and $1.3 \mathrm{~Hz}$ in the transverse motion. Also the wave forms of all the four acceleration records during the A- Earthquake are very simple with one predominant frequency. It is also understood from Table 2 that in the $\mathrm{B}$-Earthquake the predominant frequencies of both the ground and pier motions are approximately $1.6 \mathrm{~Hz}$ in the transverse direction. In the longitudinal direction, however, the pier motion has several predominant frequencies. The most predominant one is approximately $1.8 \mathrm{~Hz}$ which is again very close to the predominant frequency of the ground motion of $1.9 \mathrm{~Hz}$. As is the case of A-Earthquake, the acceleration records on the ground in the both directions and the acceleration record on the pier top in the transverse direction are very simple with a single predominant frequency. On the other hand, the records during the C-Earthquake are somewhat different from those for the A and BEarthquakes described as above. The most predominant frequencies of the ground motions are approximately $3.7 \mathrm{~Hz}$ in both the longitudinal and transverse directions which are different from those of pier motions, i.e. approximately $1.4 \mathrm{~Hz}$ in both directions. It should be noted here, however, that the ground motions have a predominant frequency close to the $1.4 \mathrm{~Hz}$ although they are not the most predaminant.

It can be recognized from these results that the acceleration records of the pier always contained motions in the range of $1.3-1.7 \mathrm{~Hz}$ as the most predominant ones in both the longitudinal and transverse directions. The frequencies in the range of $1.3-1.7 \mathrm{~Hz}$, however, can not be considered to be the natural frequency of the substructure, since microtremor analyses conducted during both daytime and midnight revealed that the natural frequencies of the foundation are approximately $3.8 \mathrm{~Hz}$ and $3.2 \mathrm{~Hz}$ in the longitudinal and transverse directions, respectively (refer to Table 3). On the other hand, the fundamental natural frequency of the subsurface ground on the gravel formation would be estimated approximately as

$\mathrm{f}_{\mathrm{Sl}}=\frac{\mathrm{V}_{\mathrm{S}}}{4 \mathrm{H}} \simeq \frac{130}{4 \times 18}=1.8(\mathrm{~Hz})$

\author{
$f_{s l}$ : fundamental natural frequency of the \\ subsoil during shear vibration $(\mathrm{Hz})$ \\ $\mathrm{V}_{\mathrm{S}}$ : average shear wave velocity of the \\ subsoil (m/sec.) \\ $\mathrm{H}$ : thickness of the subsurface ground (m)
}

which is considered to correspond to the lowest frequency of the subsurface ground during lowamplitude vibrations. Assuming that the shear wave velocity decreases to 70 percent of original during the high amplidude vibrations, the lowest frequency of the subsurface ground would be estimated by Eq. (1) as approximately $1.3 \mathrm{~Hz}$. It would be deduced from these considerations that the most predominant frequency that is always contained in the motions of the pier is significantly influenced by the lowest natural frequency of the sub-surface ground so that the pier vibrates almost in accordance with the motion of the subsurface ground nearby.

\section{ANALYTICAL PROCEDURE OF THE FOUNDATION}

A discrete analytical model as shown in fig. 8 was formulated to calculate earthquake responses of the embedded foundation. The equation of motions of the system can be written as

$$
\begin{aligned}
\underline{M}_{p} & \left.+\underline{M}_{e}\right) \ddot{u}_{p}+\underline{C}_{-p} \ddot{u}_{p}+\underline{k}_{p} u_{p} \\
& +\underline{C}_{e}\left(\underline{u_{p}}-\underline{u}_{g}\right)+\underline{K}_{e}\left(\underline{u_{p}}-\underline{u}_{g}\right)=\underline{0}
\end{aligned}
$$

where,

$$
\begin{aligned}
& \underline{M}_{p}: \text { mass matrix of the foundation } \\
& \underline{M}_{e}: \text { mass matrix of surrounding soils } \\
& {\underline{C_{p}}}_{p}: \text { damping matrix of the foundation } \\
& \underline{\underline{K}}_{p}: \text { stiffness matrix of the foundation } \\
& {\underline{C_{e}}}_{0}: \text { damping matrix expressing ratiational } \\
& \text { damping } \\
& \underline{K}_{e}: \text { stiffness matrix expressing springs } \\
& \text { between foundation and surrounding } \\
& \text { soils } \\
& \underline{u}_{p}, \dot{\underline{u}}_{p}, \ddot{u}_{p}: \text { absolute displacement, velocity } \\
& \text { and acceleration vectors of } \\
& \text { foundation }
\end{aligned}
$$

$\underline{u g}_{g}, \underline{\underline{u}}_{g}:$ absolute displacement and velocity vectors of subsurface ground

in which the subsurface ground motions of $\underline{u}_{g}$ and $\underline{\underline{u}}_{g}$ are assumed to be specified. Denoting as

$$
\begin{aligned}
& \underline{M}=\underline{M}_{p}+\underline{M}_{e} \\
& \underline{C}=\underline{C}_{p}+\underline{C_{e}} \\
& \underline{K}=\underline{K}_{p}+\underline{K}_{e}
\end{aligned}
$$

Eq. (2) can be written as

$$
\underline{M} \ddot{u}_{p}+\underline{C} \underline{u}_{p}+\underline{K} \underline{u}_{p}=\underline{C}_{e} \underline{\dot{u}}_{g}+K_{e} \underline{u}_{g}
$$

The vector up can be conveniently decomposed into a quasi-static displacement vector ups and a dynamic displacement vector upd, i.e.,

$$
u_{p}=\underline{u}_{p d}+\underline{u}_{p s}
$$

By definition of quasi-static displacement in the form as 
Long i tudinal

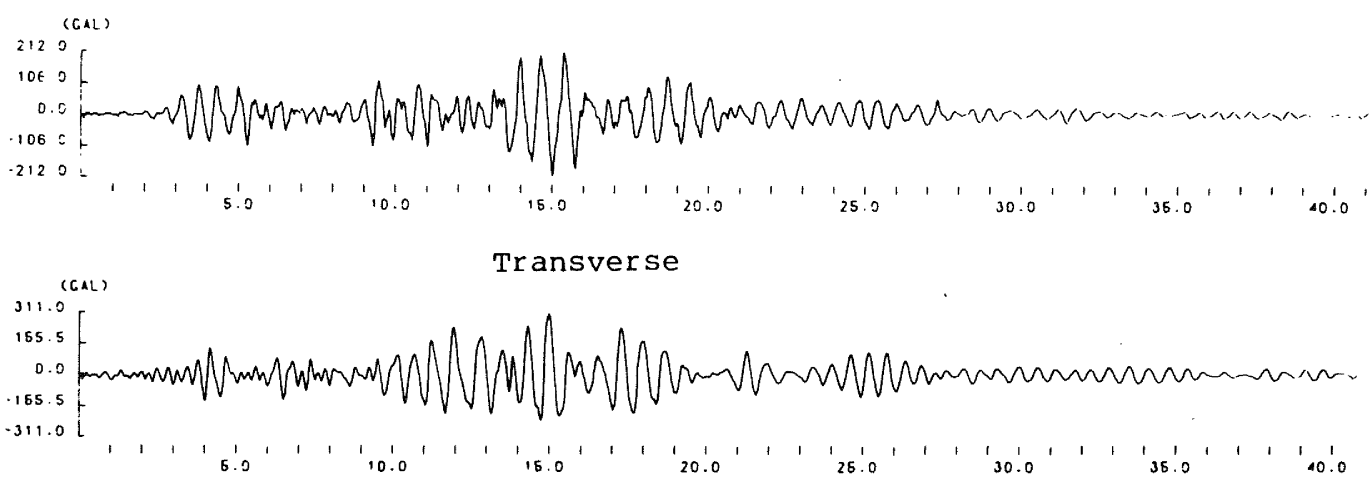

(a) AT CREST OF PIER

Longitudinal

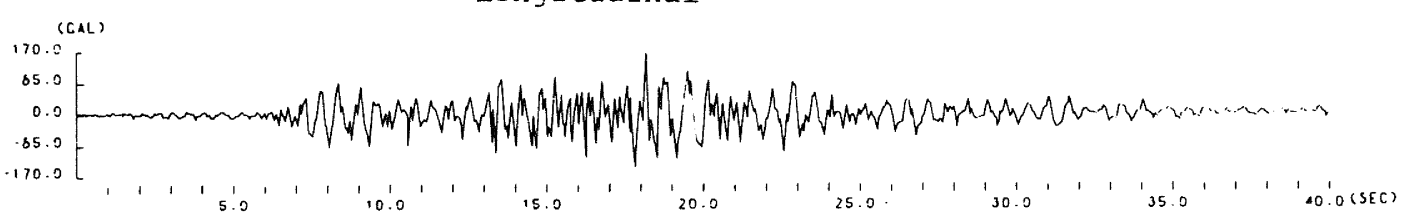

Transverse

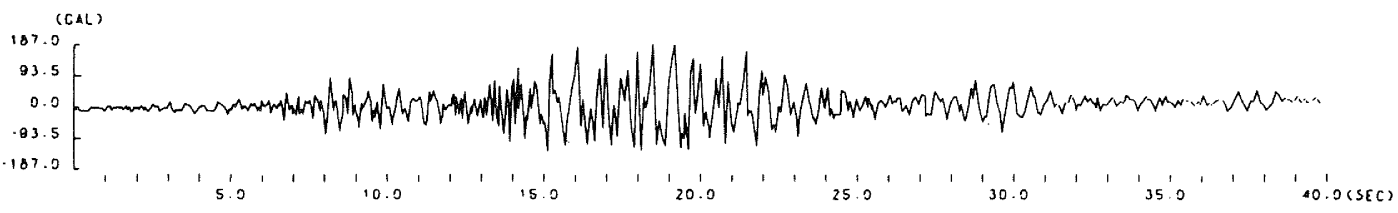

(b) ON GROUND SURFACE NEARBY

Fig. 3 ACCELERATION RECORDS AT THE ITAJIMA BRIDGE DURING THE HYUGANADA EARTHOUAKE OF APRIL 1, 1968 (A-EARTHOUAKE)
Longitudinal

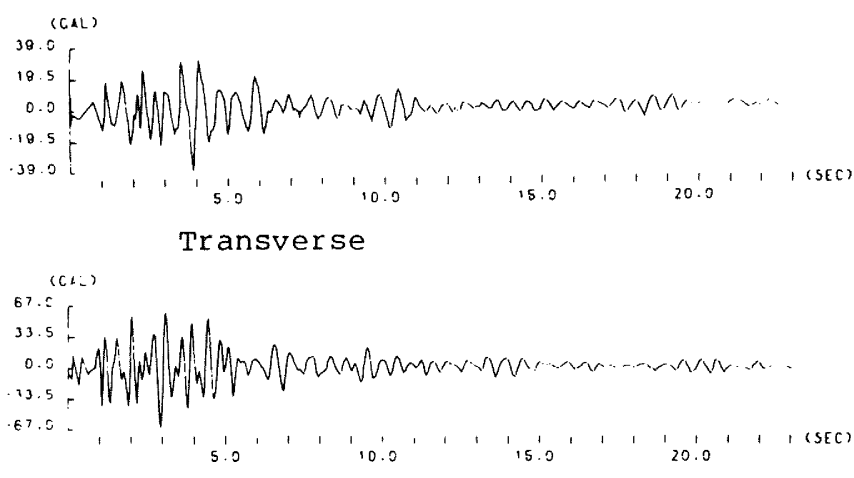

(a) AT CREST OF PIER
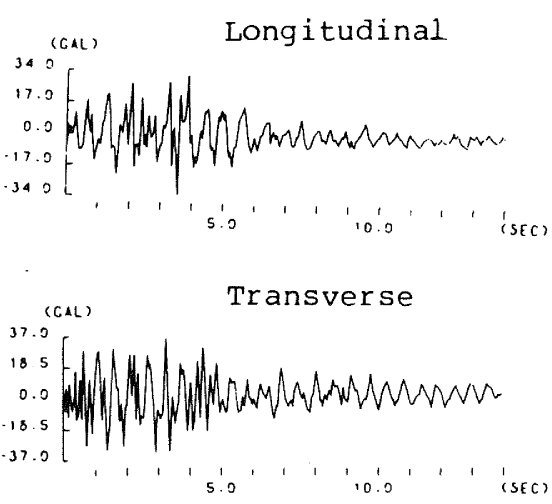

(b) ON GROUND SURFACE NEARBY

Fig. 4 ACCELERATION RECORDS AT THE ITAJIMA BRIDGE DURING AN AFTERSHOCK OF. THE HYUGANADA EARTHQUAKE OF APRIL 1, 1968 (B-EARHQUAKE) 
Long i tudinal

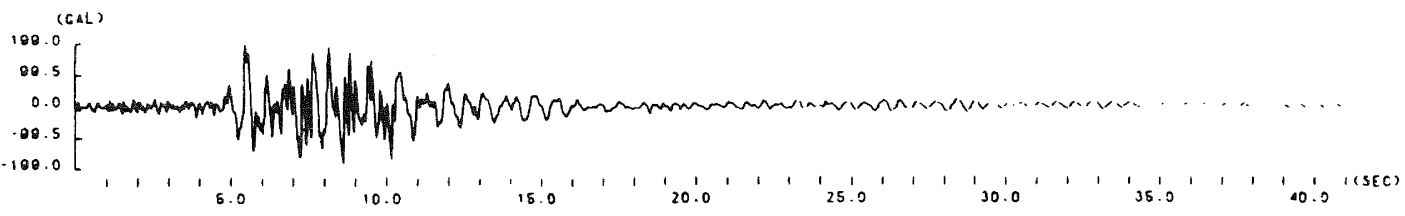

Transverse

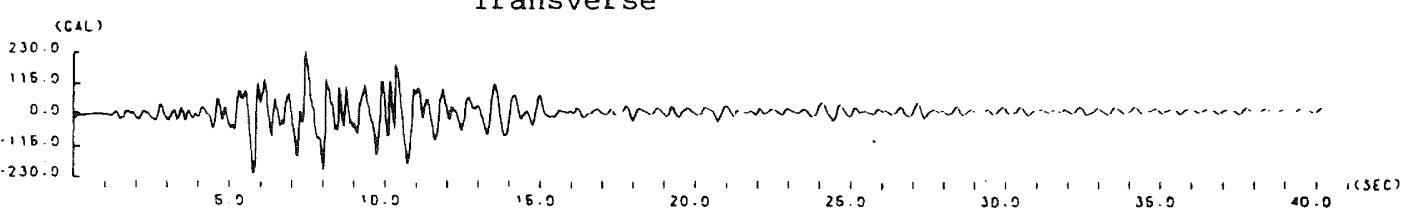

(a) AT CREST OF PIER

Long i tudinal
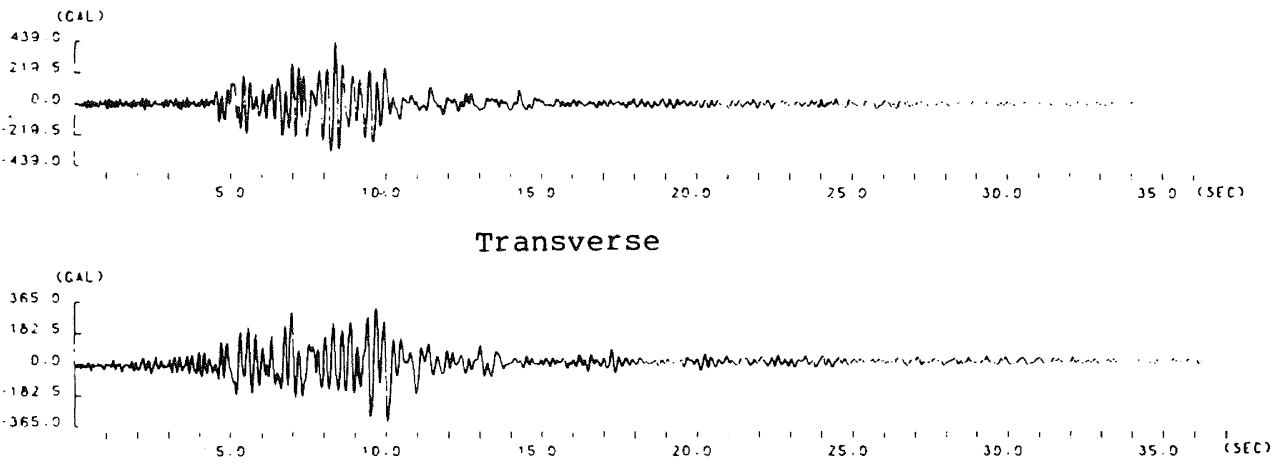

(b) ON GROUND SURFACE NEARBY

Fig. 5 ACCELERATION RECORDS AT THE ITAJIMA BRIDGE DURING THE BUNGOSUIDO EARTHQUAKE OF AUGUST 6, 1968 (C-EARTHQUAKE)

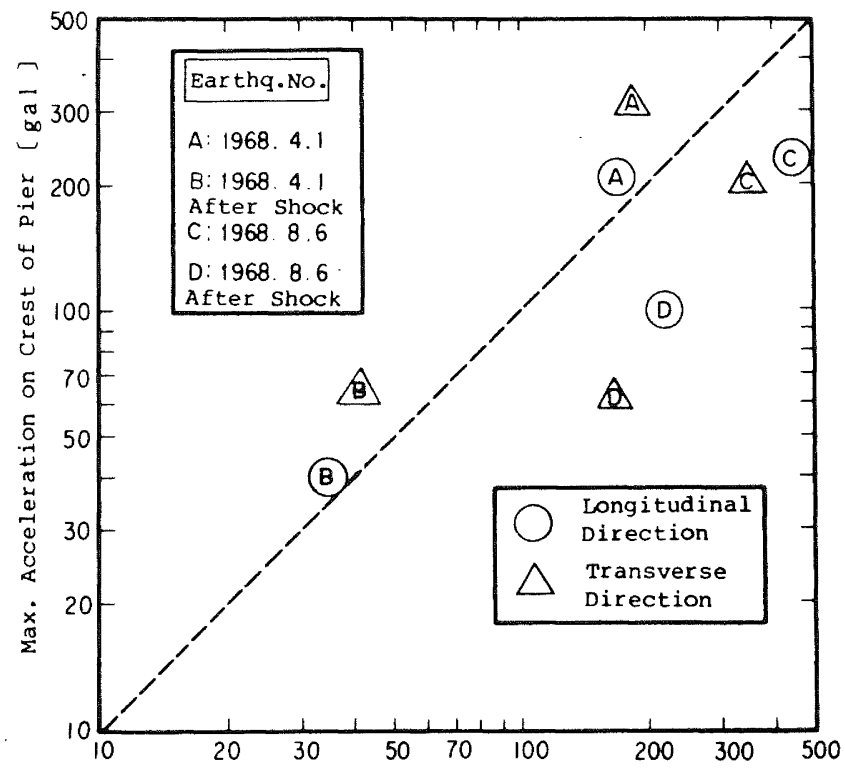

Max. Acceleration on Ground Surface Nearby [ $\mathrm{gal}$ ]

Fig. 6 AMPLIFICATIONS OF MAXIMUM ACCELERATION BETWEEN THE CREST OF PIER AND GROUND SURFACE NEARBY 


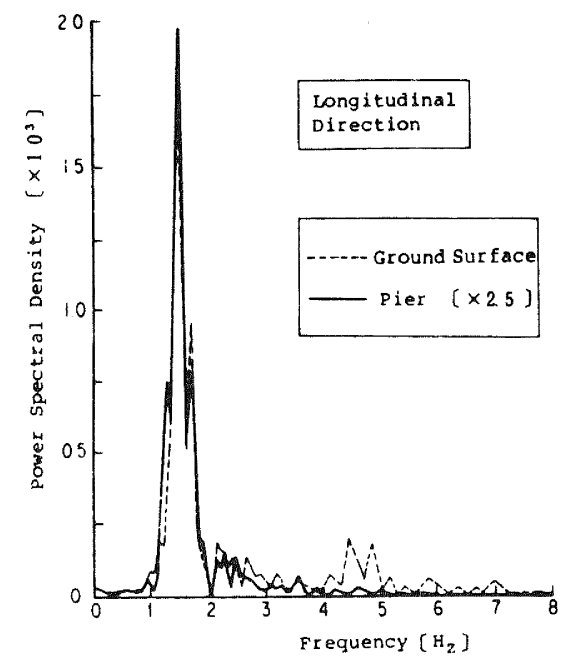

(a) Longitudinal Direction

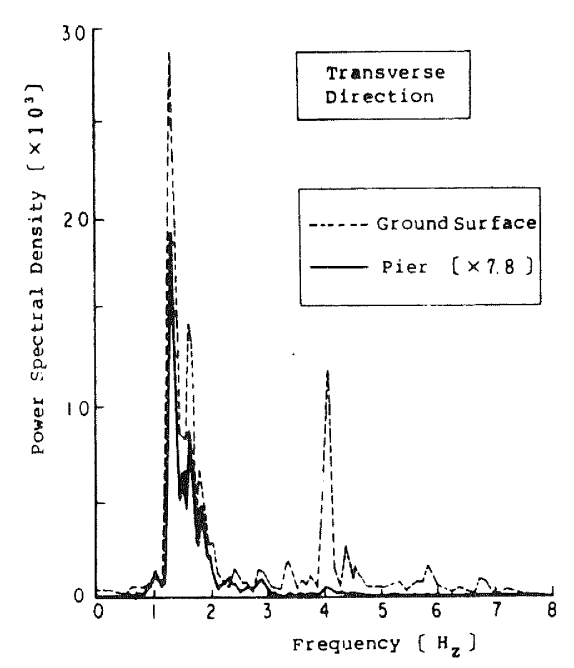

(b) Transverse Direction

(1) THE HYUGANADA EARTHQUAKE
(A-EARTHQUAKE)

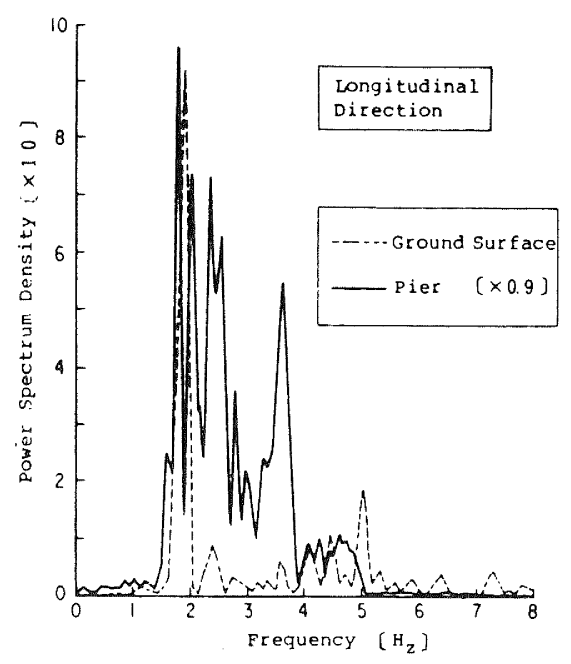

(a) Longitudinal Motion

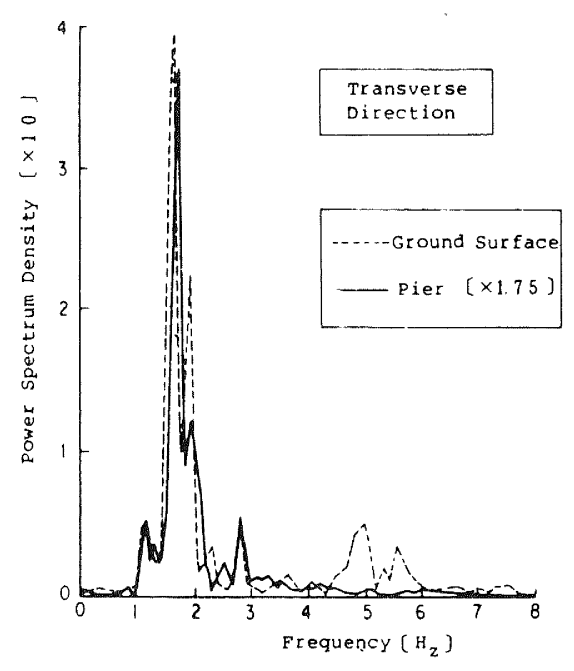

(b) Transverse Motion

(2) AN AFTERSHOCK OF THE
HYUGANADA EARTHQUAKE (B-EARTHQUAKE)

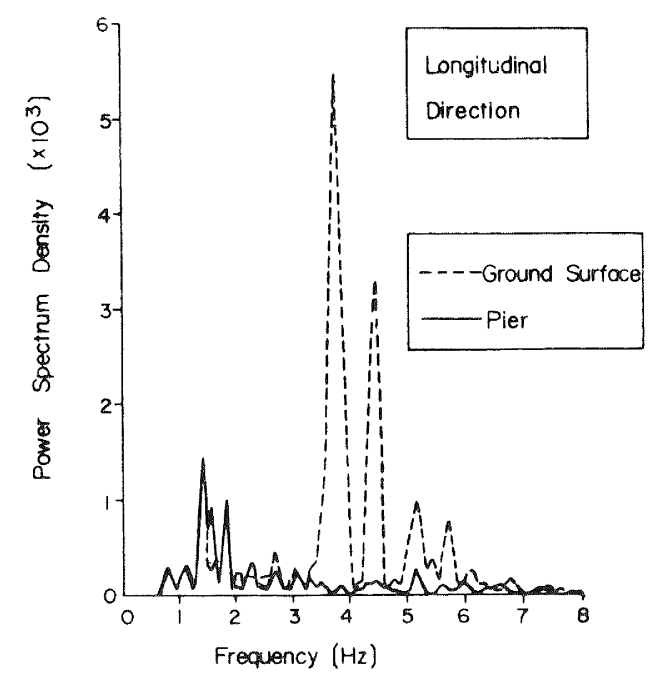

(a) Longitudinal Motion

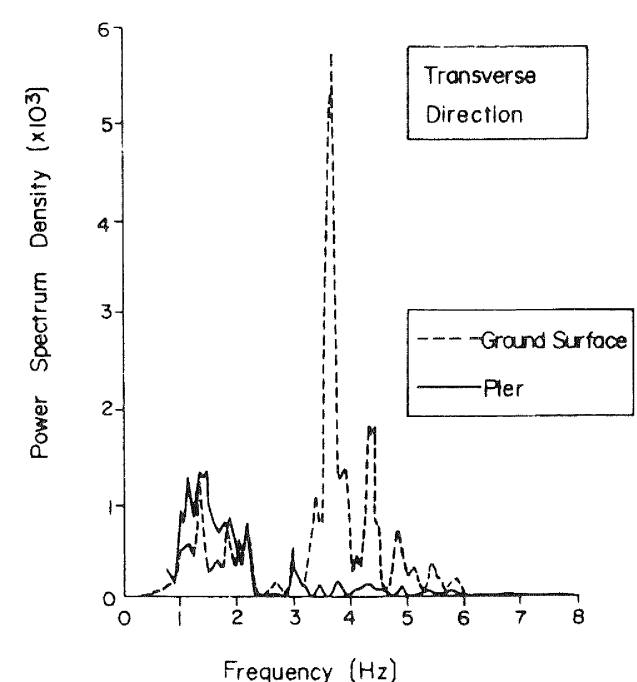

(b) Transverse Motion

(3) THE BUNGOSUIDO EARTHQUAKE

Fig. 7 POWER SPECTRA OF ACCELERATION RECORDS AT THE ITAJIMA BRIDGE 


$$
\underline{\mathrm{K}} \underline{u}_{\mathrm{p}} \mathrm{s}+\underline{\mathrm{K}}_{\mathrm{e}} \underline{u}_{\mathrm{g}}=\underline{0}
$$

ups can be written as

$$
\underline{u}_{p s}=-\underline{K}^{-1} \underline{K}_{e} u_{g}=-\underline{K}_{s} \underline{u}_{g}
$$

Substitutions of Eqs. (5) and (6) into Eq. (4) gives $\underline{M} \underline{\underline{u}}_{p d}+\underline{\mathrm{C}} \underline{\underline{u}}_{p d}+\underline{\mathrm{K}} \underline{u}_{p d}=\underline{\mathrm{M}} \underline{\mathrm{K}}_{S} \underline{\ddot{u}}_{g}+\left(\underline{\mathrm{C}}_{e}+\underline{\mathrm{C}} \underline{\mathrm{K}}_{\mathrm{S}}\right) \dot{\underline{u}}_{g}$ Usually the damping term on the right hand side of Eq. (8) is less significant comparing with the inertia terms so that it can be dropped from the equation without introducing significant errors. Then Eq. (8) can be written as

$$
\underline{M} \underline{\ddot{z} p d}+\underline{\mathrm{C}} \underline{\underline{u}} \mathrm{pd}+\underline{\mathrm{K}} \underline{\underline{u} p d}=\underline{\mathrm{M}} \underline{K}_{s} \underline{\ddot{u}}_{g}
$$

Eq. (9) can be solved by mode-superposition procedures provided that the damping matrix on the left hand side of the equation is assumed to be triangulalized in the same manner as the mass and stiffness matrixes in the form of damping ratio of critical, i.e.,

$$
\begin{aligned}
& \underline{\Phi} \underline{\mathrm{M}} \Phi=\underline{I} \\
& \underline{\Phi} \underline{\mathrm{K}} \Phi=\Omega^{2} \\
& \underline{\Phi} \underline{\mathrm{C}} \Phi=\underline{\Lambda}
\end{aligned}
$$

where

$$
\begin{aligned}
& \underline{\Phi}: \text { modal matrix } \\
& \underline{I}: \text { identity matrix } \\
& \underline{\Omega}^{2}=\operatorname{diag}\left(\mathrm{w}_{i}{ }^{2}\right) \\
& \underline{\Lambda}^{2}=\operatorname{diag}\left(2 \mathrm{~h}_{i} \mathrm{w}_{j}\right) \\
& \mathrm{w}_{i}: \text { i-th undarqued natural frequency } \\
& \mathrm{h}_{i}: \text { i-th damping ratio of critical }
\end{aligned}
$$

Then denoting uspd, ippd and $\ddot{u}_{p d}$ by the normal coordinates as

$$
\underline{u} p d=\underline{\Phi}, \underline{\underline{x}} \underline{p d}=\underline{\Phi} \underline{x}, \underline{\dot{u} p d}=\underline{\Phi} \underline{\ddot{x}}
$$

Eq. (9) can be written in the following form.

$$
\underline{\ddot{x}}+\underline{\Lambda} \dot{x}+\underline{\Omega}^{2} \underline{x}=\underline{R}
$$

where

$$
\underline{\mathrm{R}}=-\Phi^{\mathrm{T}} \underline{\mathrm{Mü}} \mathrm{pd}
$$

Equation (12) is a uncoupled squation of motion and the i-th normal coordinate can be solved by the Duhamel Integration as

$$
\begin{array}{r}
x_{i}=\frac{1}{w_{i} \sqrt{1-h_{i}^{2}}} t_{0} R_{i}(\tau) e^{-h_{i} w_{i}(t-\tau),} \\
\sin \left(\sqrt{1-h_{i}^{2} w_{i}}(t-\tau) d \tau\right.
\end{array}
$$

\section{CALCULATION OF PIER MOTIONS}

The pier motions were computed by using the analytical procedure described in the preceeding paragraph based on the measured ground motions for the A, B and C-Earthquakes and they were compared with the measured motions. The correlations were conducted only for the motions in the longitudinal direction since conditions of the superstructure supports in this direction were considered to be well defined as compared with the complex conditions in the transverse direction, i.e., in the longitudinal direction one of the two girders supported on the pier was rigidly connected to the pier and another girder was supported by a sliding support.

The base-rock motions was computed from the measured ground surface motions by the deconvolution procedure taking account of the strain dependence of the shear moduli and hysteretic damping ratios of the subsoils. The subsoils and foundation were idealized by a one-dimensional shear column model with equivalent linear soil properties and one-dimensional elastic beam supported elastically by the surrounding subsoils, respectively. The weight of a girder rigidly supported by the pier was idealized as an additional mass lumped at the crest of pier. In the analyses the effects of another girder which is supported by the sliding support were disregarded since it was considered that the frictional forces acting at the sliding support were relatively less significant. The lowest natural frequencies of the pier and surrounding subsoils thus estimated are shown in Table 4.

The response accelerations of the pier were then calculated based on Eq. (2) by applying the base-rock motions at the bottom of the shear column model of subsoils. The comparative plots of both the theoretical and measured accelerations at the crest of pier are shown in fig. 9 for the $\mathrm{A}, \mathrm{B}$ and C-Earthquakes. The damping ratios assumed in the analyses are shown in Table 4. It is recognized from the results that fairly good agreements are obtained for the motions in the $\mathrm{A}$ and $\mathrm{B}$-Earthquakes. On the other hand, a poor correlation was achieved for the motion in the C-Earthquake and further precise investigations are needed to clarify the frequency characteristics of the foundation.

\section{CONCLUSTONS}

Based on the results presented, the following conclusions may be deducted:

Seismic responses of the deeply embedded foundation are significantly influenced by the effects of surrounding subsurface soils. Provided that the lowest natural frequency of the surrounding subsoils, the motions of foundation are significantly prescribed by the motions of the surrounding subsoils.

(2) Seismic response accelerations of the foundation can be calculated with fairly good accuracy by the analytical procedure presented herein from the free-field ground accelerations measured near the foundation for earthquakes which induce ground accelerations at the bridge site with the most predominant frequencies lower than the fundamental natural frequency of the foundation.

\section{REFERENCES:}

1. Iwasaki, T.: Earthquake-Resistant Design of Bridges in Japan, Bulletin of Public Works 


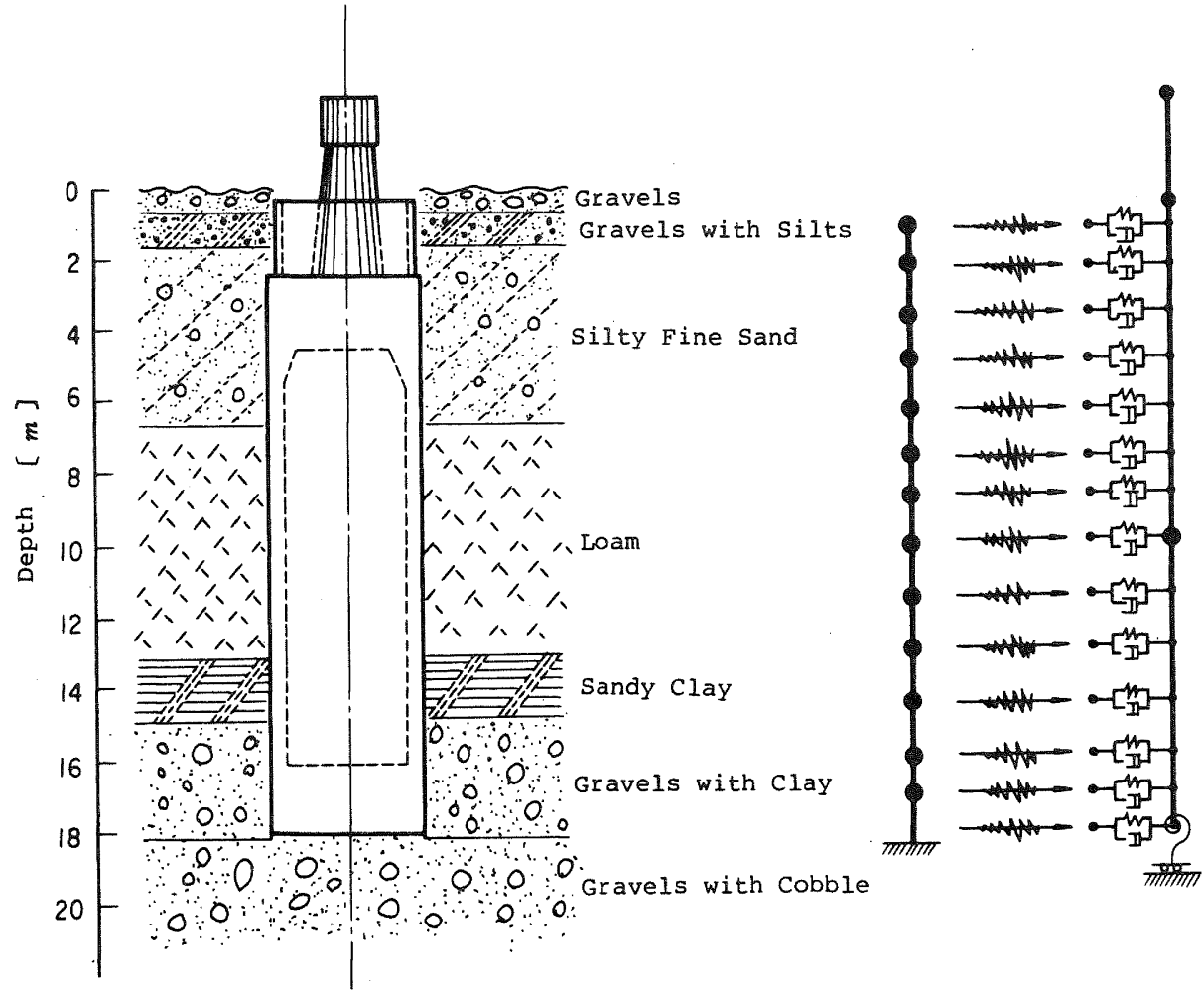

(a) Caisson-Pier and Surrounding Subsoils

(b) Analytical Model

Fig. 8 ANALYTICAL MODEL OF FOUNDATION OF THE ITAJIMA BRIDGE

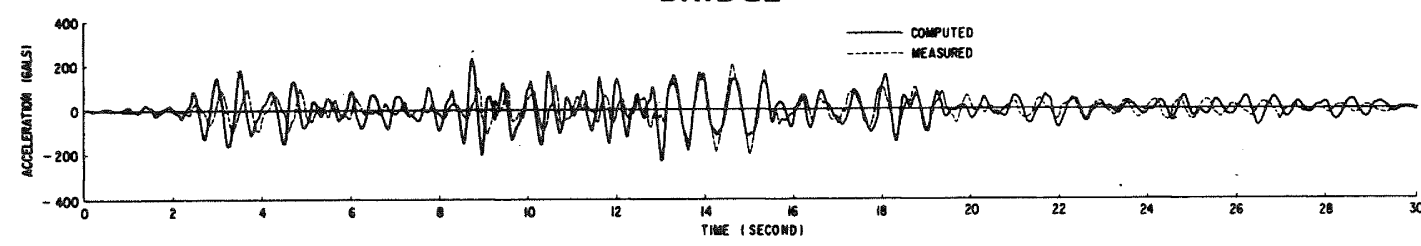

(a) HYUGANADA EARTHQUAKE (A-EARTHQUAKE)

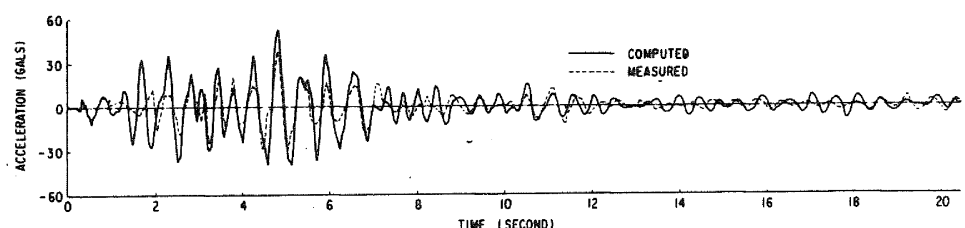

(b) AFTERSHOCK OF THE HYUGANADA EARTHQUAKE (B-EARTHQUAKE)

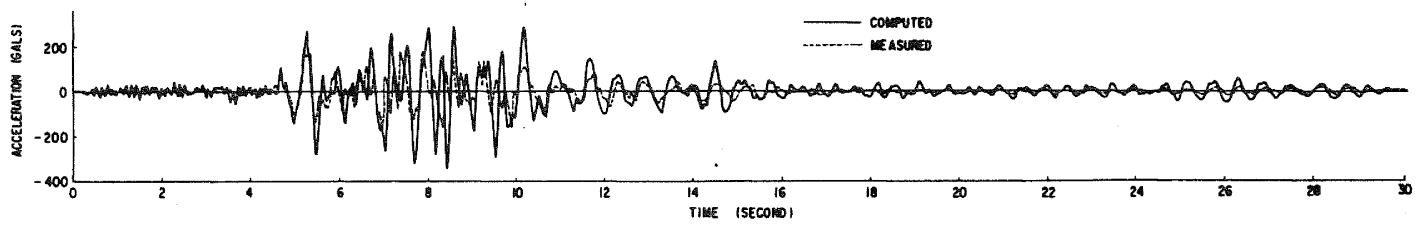

(c) BUNGOSUIDO EARTHOUAKE (C-EARTHQUAKE)

Fig. 9 CORRELATIONS OF SEISMIC RESPONSE ACCELERATION AT THE CREST OF ITAJIMA BRIDGE (LONGITUDINAL ACCELERATIONS) 
Research Institute, Ministry of Construction, May 1973.

2. Kuribayashi, E. and Iwasaki, T.: Dynamic Properties of Highway Bridges, 5th World Conference on Earthquake Engineering, Rome, December 1972.

3. Iwasaki, T., Kawashima, K. and Takagi, Y.: Influences of The Surrounding Subsoils on Seismic Responses of Highway Bridge Foundation, Technical Memorandum No. 1372, Public Works Research Institute, Ministry of Construction, May 1978 (in Japanese).

This paper was presented at the South Pacific Regional Conference on Earthquake Engineering, Wellington May 1979.

Table 1 STRONG MOTION ACCELERATION RECORDS AT ITAJIMA BRIDGE

\begin{tabular}{|c|c|c|c|c|c|c|c|c|}
\hline \multirow{3}{*}{$\begin{array}{l}\text { Ear thquake } \\
\text { No. }\end{array}$} & \multirow{3}{*}{ Ear thquake } & \multirow{3}{*}{ Date } & \multirow{3}{*}{$\begin{array}{l}\text { Richter } \\
\text { Magnitude }\end{array}$} & \multirow{3}{*}{$\begin{array}{c}\text { Epicentral } \\
\text { Distance } \\
(\mathrm{km})\end{array}$} & \multicolumn{4}{|c|}{ Maximum Accelerations (Gal) } \\
\hline & & & & & \multicolumn{2}{|c|}{ Pier Motion } & \multicolumn{2}{|c|}{ Ground Surface Motion } \\
\hline & & & & & Long i tudinal* & Transverse" & Long i tud inal* & Transuerse * \\
\hline A & $\begin{array}{r}\text { The Hyuganada } \\
\text { Earthquake }\end{array}$ & April 1,1978 & 7.5 & 100 & 219 & 310 & 170 & 186 \\
\hline B & $\begin{array}{c}\text { The Hyuganada } \\
\text { Eart thquake } \\
\text { (Afterstock) }\end{array}$ & Apri1 1,1978 & 6.3 & 100 & 39 & 66 & 35 & 42 \\
\hline c & $\begin{array}{r}\text { The Bungosuido } \\
\text { Earthguake }\end{array}$ & August 6,1978 & 6.6 & 11 & 198 & 230 & 438 & 365 \\
\hline D & $\begin{array}{c}\text { The Bungosuido } \\
\text { Earthquake } \\
\text { (Aftershock) }\end{array}$ & August 6,1978 & 5.3 & 11 & 100 & 63 & 220 & 165 \\
\hline
\end{tabular}

(Note) Longitudinal and transverse directions to the bridge axis.

Table 2 PREDOMINANT FREQUENCIES OF STRONG MOTION ACCELERATION RECORDS MEASURED ON PIER CREST AND GROUND NEARBY AT THE ITAJIMA BRIDGE (HZ)

\begin{tabular}{|c|c|c|c|c|}
\hline \multirow{2}{*}{$\begin{array}{c}\text { Ear thquake } \\
\text { No. }\end{array}$} & \multicolumn{2}{|c|}{ Longitudinal Direction } & \multicolumn{2}{|c|}{ Transverse Direction } \\
\hline & On Ground & On Pier Crest & on Ground & On Pier Crest \\
\hline А & 1.5 & 1.5 & 1.3 & 1.3 \\
\hline B & 1.9 & $\begin{array}{ll}1.8, & 2.0 \\
2.3 & 3.7\end{array}$ & 1.6 & 1.6 \\
\hline $\mathrm{c}$ & 3.7 & 1.4 & $3.7,4.4$ & 1.4 \\
\hline D & 4.2 & - & 4.4 & - \\
\hline
\end{tabular}

Table 3 PREDOMINANT FREQUENCIES ON THE PIER CREST AND GROUND SURFACE NEARBY ESTIMATED FROM MICROTREMOR ANALYSES

\begin{tabular}{|l|c|c|c|}
\hline Location & $\begin{array}{l}\text { Ground Surface } \\
\text { where Ground Motions } \\
\text { were Measured }\end{array}$ & $\begin{array}{l}\text { Ground Surface } \\
\text { around the Pier }\end{array}$ & Top of pier \\
\hline Longitudinal & 2.3 & - & 3.8 \\
\hline rransverse & 3.0 & 2.0 & 3.2 \\
\hline vertical & 4.5 & 4.0 & 6.0 \\
\hline
\end{tabular}

Table 4 LOWEST NATURAL FREQUENCIES AND DAMPING RATIOS ASSUMED

\begin{tabular}{|c|c|c|c|c|}
\hline \multirow{2}{*}{ Ear thquake No. } & \multicolumn{2}{|c|}{ Lowest Natural Frequency $(\mathrm{Hz})$} & \multirow{2}{*}{$\begin{array}{l}\text { Hysteretic Damping } \\
\text { Ratio of Subsoils } \\
\text { (8) }\end{array}$} & \multirow{2}{*}{$\begin{array}{l}\text { Radiation Damping } \\
\text { Ratio ( }(8)\end{array}$} \\
\hline & Ground & pier & & \\
\hline A & 1.6 & 2.75 & 10 & 20 \\
\hline B & 1.90 & 3.06 & 5 & 20 \\
\hline c & 1.59 & 2.66 & $8-12$ & 20 \\
\hline
\end{tabular}

